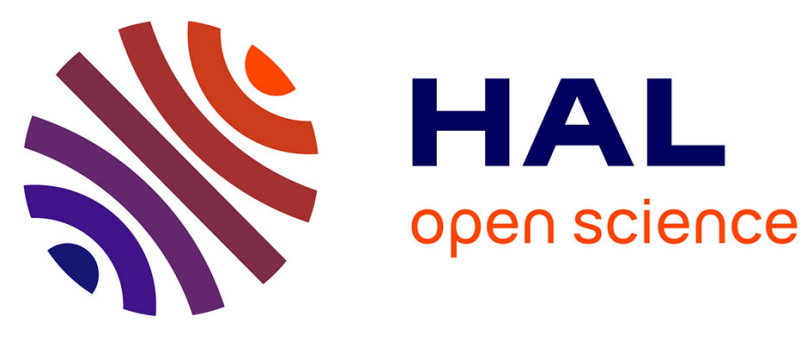

\title{
Revealing Size Dependent Structural Transitions in Supported Gold Nanoparticles in Hydrogen at Atmospheric Pressure
}

\author{
Abdallah Nassereddine, Qing Wang, David Loffreda, Christian Ricolleau, \\ Damien Alloyeau, Catherine Louis, Laurent Delannoy, Jaysen Nelayah, Hazar \\ Guesmi
}

\section{To cite this version:}

Abdallah Nassereddine, Qing Wang, David Loffreda, Christian Ricolleau, Damien Alloyeau, et al.. Revealing Size Dependent Structural Transitions in Supported Gold Nanoparticles in Hydrogen at Atmospheric Pressure. Small, 2021, pp.2104571. 10.1002/smll.202104571 . hal-03367920

\author{
HAL Id: hal-03367920 \\ https://hal.science/hal-03367920
}

Submitted on 6 Oct 2021

HAL is a multi-disciplinary open access archive for the deposit and dissemination of scientific research documents, whether they are published or not. The documents may come from teaching and research institutions in France or abroad, or from public or private research centers.
L'archive ouverte pluridisciplinaire HAL, est destinée au dépôt et à la diffusion de documents scientifiques de niveau recherche, publiés ou non, émanant des établissements d'enseignement et de recherche français ou étrangers, des laboratoires publics ou privés. 


\section{Revealing Size Dependent Structural Transitions in Supported Gold Nanoparticles in Hydrogen at Atmospheric Pressure}

Abdallah Nassereddine ${ }^{I f}$, Qing Wang ${ }^{2 f}$, David Loffreda ${ }^{3 *}$, Christian Ricolleau ${ }^{l}$, Damien Alloyeau ${ }^{1}$, Catherine Louis ${ }^{4}$, Laurent Delannoy ${ }^{4}$, Jaysen Nelayah ${ }^{1 *}$ and Hazar Guesmi ${ }^{2 *}$

${ }^{1}$ Laboratoire Matériaux et Phénomènes Quantiques, Université de Paris, CNRS, F-75013, Paris.

${ }^{2}$ ICGM, Univ. Montpellier, CNRS, ENSCM, Montpellier, France

${ }^{3}$ Univ Lyon, ENS de Lyon, CNRS UMR 5182, Université Claude Bernard Lyon 1, Laboratoire de Chimie, F-69342 Lyon, France

${ }^{4}$ Sorbonne Université, CNRS, Laboratoire de Réactivité de Surface, LRS, F-75252 Paris, France

${ }^{\mathrm{t}}$ Equal contributions

*Corresponding authors:

david.loffreda@ens-lyon.fr

jaysen.nelayah@u-paris.fr

hazar.guesmi@enscm.fr

Keywords: size dependent restructuration, gold nanoparticles, hydrogen, ETEM, AIMD

The enhancement of the catalytic activity of gold nanoparticles with their decreasing size is often attributed to the increasing proportion of low-coordinated surface sites. This correlation is based on the paradigmatic picture of working gold nanoparticles as perfect crystal forms having complete and static outer surface layers whatever their size. This picture is incomplete as catalysts can dynamically change their structure according to the reaction conditions and as such changes can be eventually size-dependent. In this work, using aberration-corrected environmental electron microscopy, we reveal for the first time size-dependent crystal structure and morphological evolution in gold nanoparticles exposed to hydrogen at atmospheric pressure, with loss of the face-centered cubic crystal structure of gold for particle size below $4 \mathrm{~nm}$. Theoretical calculations highlight the role of mobile gold atoms in the observed symmetry changes and particle reshaping in the critical size regime. An unprecedented stable surface molecular structure of hydrogenated gold decorating a highly 
distorted core is identified. By combining atomic scale in situ observations and modelling of nanoparticle structure under relevant reaction conditions, this work provides a fundamental understanding of the size-dependent reactivity of gold nanoparticles with a precise picture of their surface at working conditions.

\section{Introduction}

Many scenarios have been proposed to explain the origin of the catalytic performances of gold nanoparticles (Au NPs) in catalytic and electro-catalytic reactions. ${ }^{[1,2,3,4]}$ In particular, the higher activity of Au NPs with size smaller than $5 \mathrm{~nm}$ has been often attributed to sizedependent physical features such as the fraction of surface atoms. ${ }^{[5,6,7]}$ For instance, in reactions of hydrogenation, it is widely accepted that surface atoms on small particles are much more active than those on large particles since the fraction of low coordinated sites, i.e., at edges and corners, which are the hydrogen activation sites, increases when size decreases. ${ }^{[8,9,10,11]}$ This concept has been largely adopted for studying the reactivity of Au NPs, especially by theoreticians and surface science researchers. ${ }^{[12]}$ The common practice is to consider Au nanoparticles as perfect model crystals with well-defined symmetry and static surface facets interacting with low coverage of gas molecules. However, the effect of adsorbates, which induces surface changes is generally neglected in these studies, ${ }^{[13,14,15]}$ which is a serious drawback that may prevent reliable description of the catalyst reactivity that mainly depends on the configuration of the surface. Aside from structural effects, quantum size effects are also frequently invoked to explain the exceptional activity of gold nanoparticles. ${ }^{[16,17]}$ For instance, using Density Functional Theory, Illas et al. have reported that the minimum energy pathway of $\mathrm{O}_{2}$ dissociation for different Au NPs is chemically similar which indicates that the larger activity of smaller ones originates from electronic and not from geometric effects only. ${ }^{[17]}$ Furthermore, several other works strongly suggest that $\mathrm{Au}$ 
particles, below $\sim 2.5 \mathrm{~nm}$ in size, have non-metallic character which make them especially active in $\mathrm{H}_{2}$ chemisorption and dissociation favoring $\mathrm{H}$-rich environment promoting hydrogenation reactions. ${ }^{[18]}$ The concept of fluxionality was also reported to be one of the keys to the understanding of the peculiar reactivity of small gold clusters. ${ }^{[19,20,21]}$ Nevertheless, all these concepts and interpretations lack a tangible proof, as mechanistic understanding of the working catalyst requires access to the surface atomic evolution under relevant conditions of temperature and pressure.

The understanding of catalytic properties of Au NPs requires access with atomic resolution to the evolution of their structure under relevant conditions of temperature and pressure. Until very recently, this possibility was difficult to reach explaining the lack of a wide consensus on the mechanistic origin of the catalytic activity of Au NPs. Twenty years ago, using environmental transmission electron microscopy (ETEM), Hansen et al. have reported a landmark work evidencing shape changes in supported copper nanocrystals when exposed to low gas pressure under oxidizing and reducing conditions. ${ }^{[22]}$ This technique has since emerged as a powerful tool for real time visualization of structural evolution of materials under dynamic gas reaction conditions. With the advent of high-pressure gas cells and TEM aberration correction, ETEM nowadays enables structural dynamics to be followed in gas conditions up to atmospheric pressure with resolution down to the atomic scale. ${ }^{[23,24]}$ Additionally, ab initio molecular dynamics (AIMD) has been shown to be an efficient method for exploring the conformational three-dimensional complexity of metal NPs in presence of gas adsorbates, ${ }^{[25]}$ providing dynamic trajectories that links different possible structural changes. In this work, the structural dynamics of Au NPs with sizes ranging from $7 \mathrm{~nm}$ to 1.5 $\mathrm{nm}$ supported on anatase-type titanium oxide (Figure S1, Supporting Information) was examined for the first time, by ETEM at the atomic scale upon exposure to $\mathrm{H}_{2}$ at atmospheric pressure and at various temperatures. In situ atomic scale observations of individual Au NPs 
complemented with ex situ TEM observations, show supported fcc Au NPs undergoing dramatic structural changes in $\mathrm{H}_{2}$ when their size is smaller than $\sim 4 \mathrm{~nm}$. AIMD simulations disclose the atomic behavior driving the structural changes under $\mathrm{H}_{2}$ observed in such NPs and provide a precise picture of the hydrogenated gold surface at the molecular level.

\section{Results and Discussion}

Figure 1 shows series of in situ high angle annular dark field scanning ETEM (HAADF STEM) side-view images of three Au NPs with size ranging from $4.5 \mathrm{~nm}$ to $3 \mathrm{~nm}$ under $10^{5}$ $\mathrm{Pa} \mathrm{H}_{2}$. Figure 1a and $1 \mathrm{~b}$ compare the structural evolution of a $\sim 4.5 \mathrm{~nm}$ (a) and a $\sim 3 \mathrm{~nm}(\mathrm{~b}$ ) truncated octahedron (TOh) Au NP when they are cooled from 400 to $25{ }^{\circ} \mathrm{C}$ in $\mathrm{H}_{2}$. The full series of in situ HAADF and bright-field (BF) STEM images acquired on these two NPs are provided in (Figure S2 and S3 respectively, Supporting Information) and all experimental details are described in the Methods section. Under $\mathrm{H}_{2}$ exposure, size-dependent structural changes of $\mathrm{Au}$ NPs are revealed. As reported in Figure 1a and (Figure S2, Supporting Information), the gold NP of $\sim 4.5 \mathrm{~nm}$ is found to roughly retain its initial shape and its fcc structure down to $25{ }^{\circ} \mathrm{C}$. Similar results are found for a larger NP presented in (Figure S4, Supporting Information). In contrast, both the shape and the structure symmetry of the Au NP with $3 \mathrm{~nm}$ size drastically evolve upon exposure to $\mathrm{H}_{2}$ at $400^{\circ} \mathrm{C}$ (Figure $1 \mathrm{~b}$ and Figure $\mathrm{S} 3$, Supporting Information). Indeed, comparison of STEM image simulations with experimental in situ data shows that the initial fcc structure transform into icosahedron (Figure S5, Supporting Information) with the five-fold icosahedral symmetry remaining stable as temperature is reduced to $200{ }^{\circ} \mathrm{C}$. Additional in situ ETEM observations of another 3-nm Au NP in $10^{5} \mathrm{~Pa} \mathrm{H}_{2}$ at $175{ }^{\circ} \mathrm{C}$ show instead a non-fcc structure with unidentified symmetry evolving in the presence of hydrogen (Figure 1c). As illustrated by the HAADF STEM images extracted from a time-lapse video recording (Video S1, Supporting Information), the 
structure of this Au NP fluctuates continuously between different structural isomers with shape in projection remaining roughly spherical during the course of the video recording (144 seconds duration).
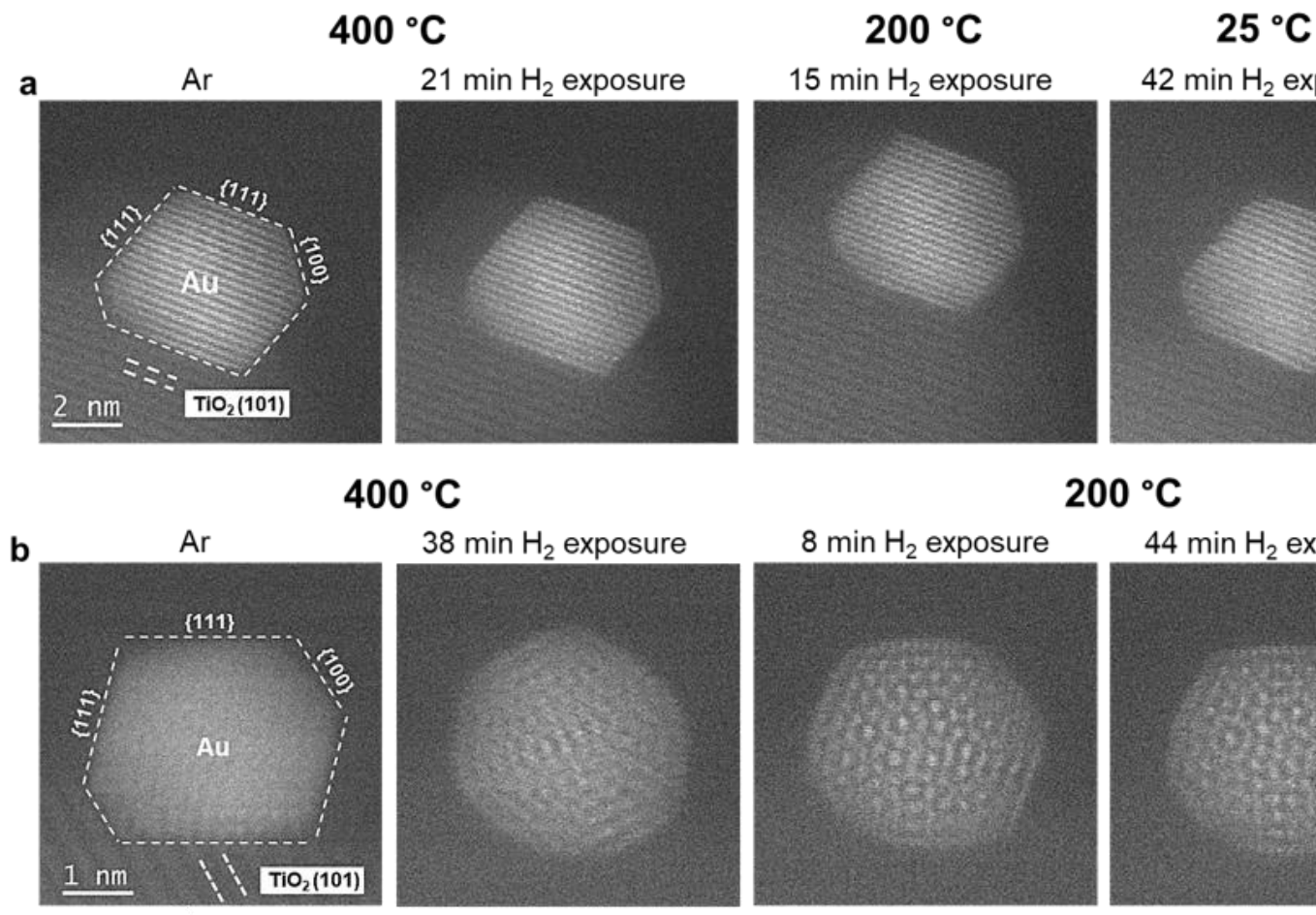

$400{ }^{\circ} \mathrm{C}$
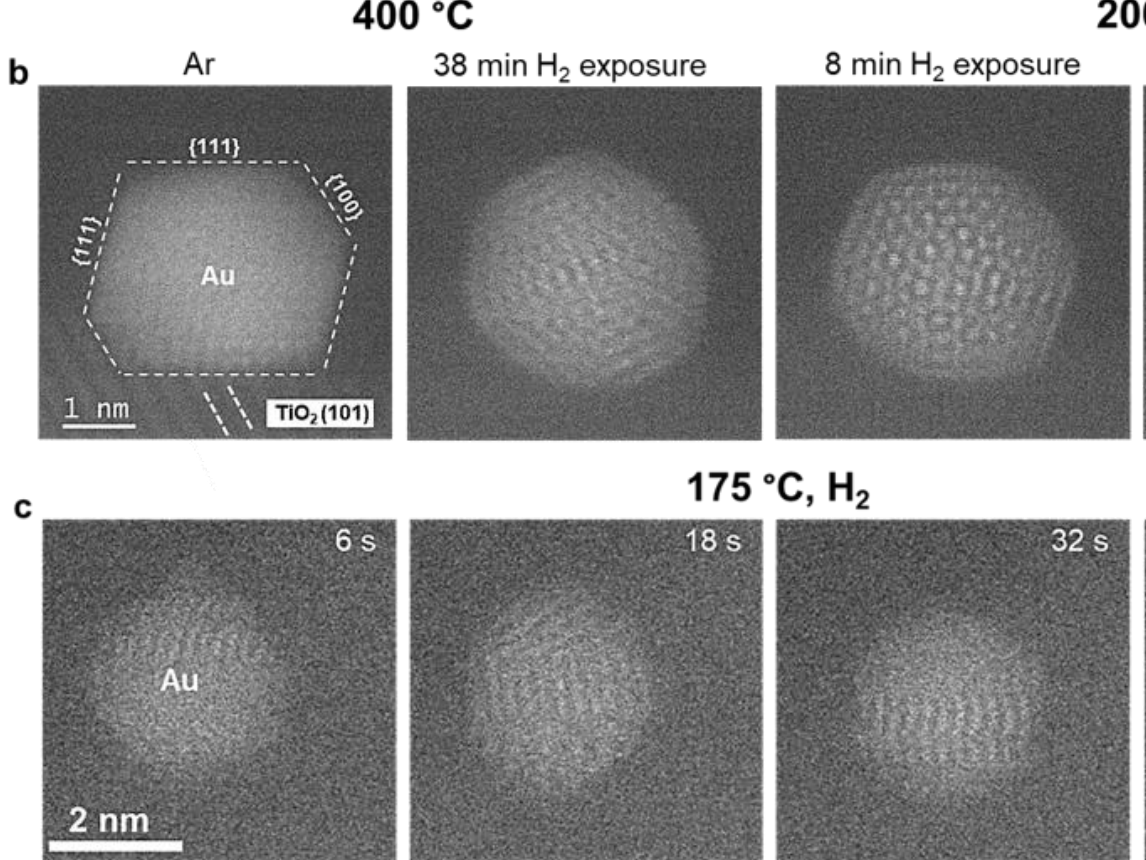

42 min $\mathrm{H}_{2}$ exposure

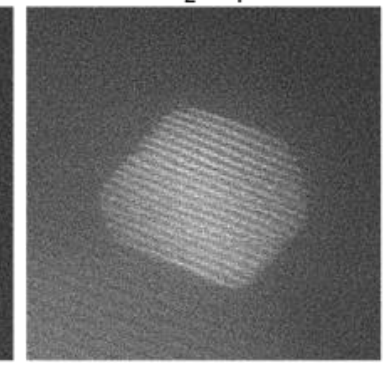

$200{ }^{\circ} \mathrm{C}$
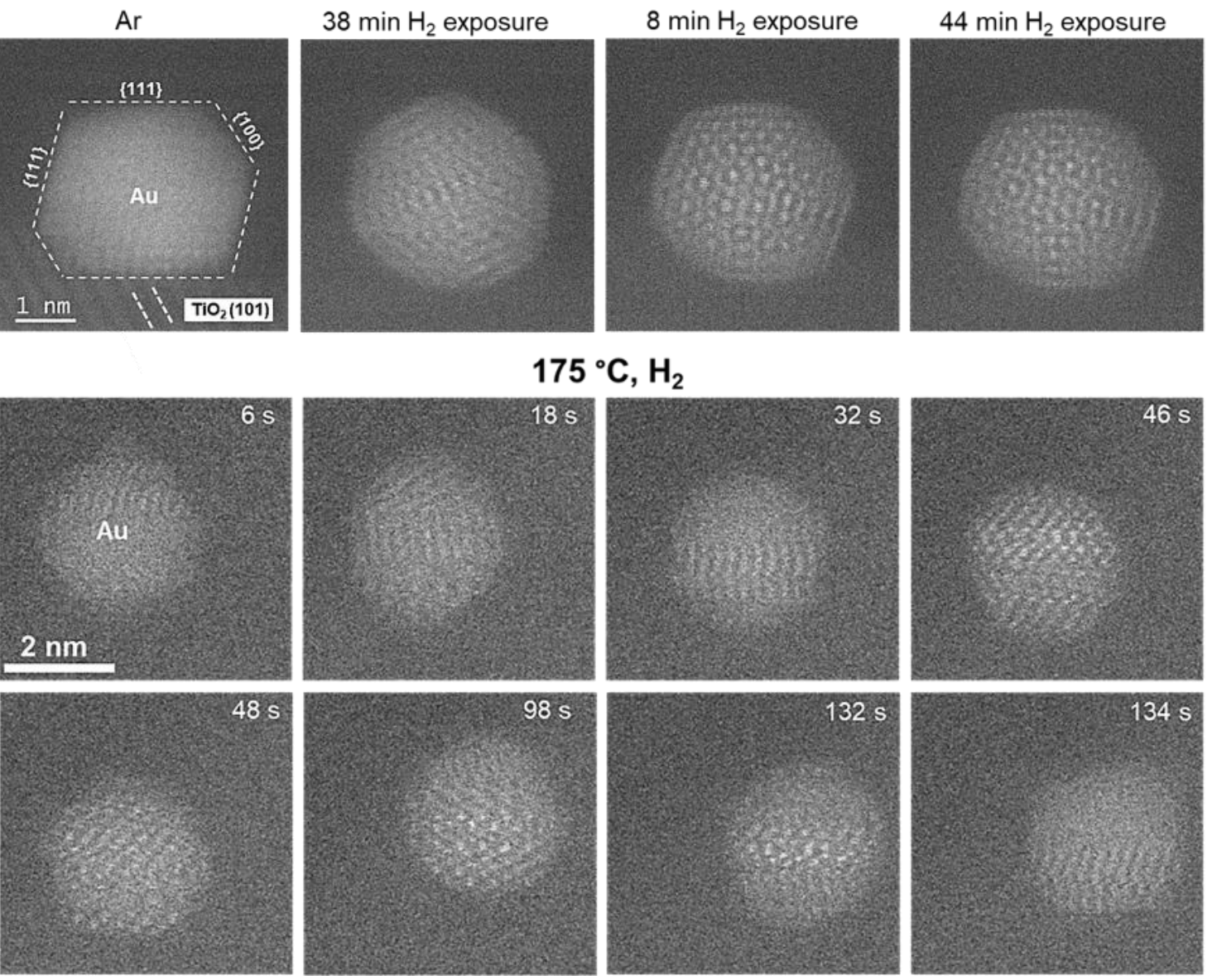

Figure 1. Direct atomic scale visualization of the size-dependent structural evolution of Au NPs supported on anatase-type titania in $\mathrm{H}_{2}$ at atmospheric pressure. a-c) Time- and temperature resolved in situ HAADF STEM images reveal distinct structure transformation pathways for NPs greater than $4 \mathrm{~nm}$ (a) and smaller than $4 \mathrm{~nm}$ (b,c). Prior to $\mathrm{H}_{2}$ exposure and as a reference experiment, the two NPs were individually imaged in $40 \mathrm{~Pa}$ argon (near-vacuum condition) at $400{ }^{\circ} \mathrm{C}$. In situ HAADF STEM imaging of a $~ 4.5-\mathrm{nm}$ Au NP (a) and a $~ 3-\mathrm{nm} \mathrm{Au}$ $\mathrm{NP}$ (b) are sequentially acquired in $40 \mathrm{~Pa} \mathrm{Ar}$ at $400{ }^{\circ} \mathrm{C}$ then in $10^{5} \mathrm{~Pa} \mathrm{H}_{2}$ at 400,200 and $25{ }^{\circ} \mathrm{C}$. The broken white lines highlight the projected truncated octahedral equilibrium shapes of both NPs in Ar at $400{ }^{\circ} \mathrm{C}$. The 
NPs are in (111) epitaxy onto $\mathrm{TiO}_{2}$ and viewed close to the [101] direction of the fcc structure (see fast Fourier transforms of corresponding STEM images in (Figure S2c and S3c, Supporting Information). In $\mathrm{H}_{2}$, the 4.5-nm NP remains stable down to $25{ }^{\circ} \mathrm{C}$ while the $3-\mathrm{nm}$ NP restructures at $400{ }^{\circ} \mathrm{C}$, leading to changes in both its structure and shape with the observation of an icosahedral structure under $\mathrm{H}_{2}$ as from $400{ }^{\circ} \mathrm{C}$. c) Sequential in situ STEM images of another $\sim 3 \mathrm{~nm} \mathrm{Au} \mathrm{NP}$ in $10^{5} \mathrm{~Pa} \mathrm{H}_{2}$ at $175^{\circ} \mathrm{C}$, showing a round-shape particle undergoing continuous restructuring under $\mathrm{H}_{2}$ (captured from Video $\mathrm{S} 1$, Supporting Information).
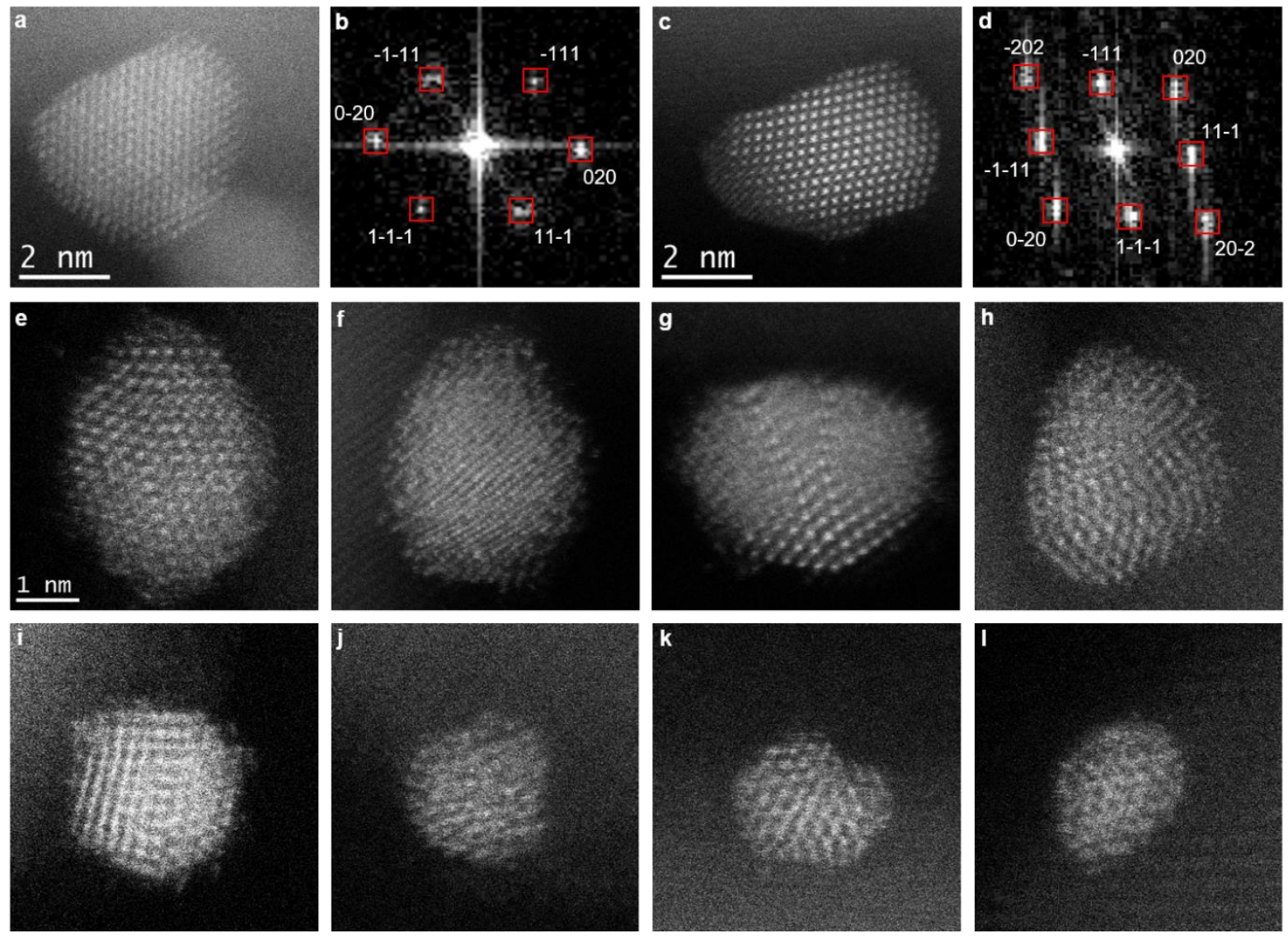

Figure 2. Atomic scale $\mathrm{STEM}$ imaging of $\mathrm{TiO}_{2}$ supported $\mathrm{Au}$ NPs after ex situ exposure to $\mathrm{H}_{2}$ at atmospheric pressure at 400 and $200{ }^{\circ} \mathrm{C}$. Ex situ exposure to hydrogen is conducted on the same starting materials used for in situ experiments in (Figure 1). Gas pressure and temperature conditions for ex situ experiment are consistent with in situ ones (see Experimental Section). TEM pressure during STEM image acquisition, $\approx 10^{-6} \mathrm{~Pa}$. Particle size decreases from (a) to (l). The scale, $1 \mathrm{~nm}$, in (e) is common to all subsequent Figures. a, c) 4.3-nm and 4.1$\mathrm{nm}$ particles with fcc structure (FFT in (b) and (d) respectively). e-1) For particle size below $\sim 4 \mathrm{~nm}$, highly distorted non fcc structures are observed.

In order to further investigate the size-dependent structural evolution of gold nanoparticles when exposed to $\mathrm{H}_{2}$, we perform complementary ex situ STEM imaging under vacuum and at room temperature to analyze the local structures of $\mathrm{Au}$ NPs previously exposed to $\mathrm{H}_{2}$ in a fixed-bed reactor under pressure and heating conditions close to those of in situ TEM 
observations (see Experimental section). Figure 2 shows atomic scale ex situ HAADF STEM images of typical NPs exposed ex situ to $\mathrm{H}_{2}$. The analysis of the structure of 61 NPs clearly identifies a critical particle size around 3-4 nm. While particles with size greater than $4 \mathrm{~nm}$ display perfect fcc structure bounded by well-defined facets (Figure 2a-c), ex situ TEM identifies various non-fcc structures for sizes smaller than $4 \mathrm{~nm}$. We observe particles with a core reminiscent of an fcc order (core showing lattice deformation) and a highly-disordered surface (Figure 2e-f), NPs showing five-fold symmetries (Figure 2g) and disordered structure NPs (Figure 2h-1). Ex situ TEM observations thus provide evidences of the important effect of adsorbed hydrogen on the structural transition of gold NPs being size-dependent. Based on these both ex situ and in situ TEM, we can firmly state that NPs below 4-3 nm undergo substantial structure evolution when exposed to $\mathrm{H}_{2}$, resulting in the loss of their fcc arrangement. In contrast, $\mathrm{H}_{2}$ exposure has roughly no effect on the structure of Au NPs with size above $4 \mathrm{~nm}$, which is in line with theoretical results predicting that low index gold surfaces as those forming the surface of TOh NPs are unable to instantly adsorb $\mathrm{H}_{2} \cdot{ }^{[15,26,27]}$ These experimental observations provide the first evidence of particle size dependent structural transformation of gold NP under hydrogen. Moreover, while hydrogen adsorption on $\mathrm{Au}$ NPs has already been demonstrated by DFT calculations and spectroscopic measurements, ${ }^{[28,29]}$ the adsorption inducing structural transformation had never been directly observed.

In order to understand the atomic origin of the structural changes observed experimentally in small sized Au NPs under hydrogen pressure, we performed AIMD simulations of model TOh hydrogen-covered Au NPs at $500 \mathrm{~K}\left(227^{\circ} \mathrm{C}\right)$ and at $300 \mathrm{~K}\left(27^{\circ} \mathrm{C}\right)$. We follow the structural evolution dynamics of Au NPs of 201-atom ( 2 nm) in vacuum (denoted as TOh_Au $\left.\mathrm{Au}_{201}\right)$ and with a coverage of $1 \mathrm{ML}$ atomic hydrogen (denoted as $\mathrm{TOh} \_\mathrm{Au}_{201} \mathrm{H}_{122}$ and corresponding to the adsorption of $122 \mathrm{H}$ atoms, see Methods). The AIMD simulations show a strong evolution 
of the structure of the Au NP induced by the adsorption of atomic hydrogen on its surface (Video S2, Supporting Information). Within few ps of dynamics performed at 500K, the TOh_Au ${ }_{201} \mathrm{H}_{122}$ NP (Figure 3a, configuration A) loses its TOh equilibrium shape and transforms into a rounded shape NP with a highly distorted non-fcc structure (Figure 3a, configuration B), which is primarily caused by surface motion and extraction of $\mathrm{Au}$ atoms induced by the adsorption of hydrogen. The fcc to non-fcc structure transition is evidenced by examining the distribution of $\mathrm{Au}$ atom distances with respect to the mass center of the NP. As depicted in Figure $3 b$, the well-defined peaks of $\mathrm{TOh} \_\mathrm{Au}_{201}$ signature of fcc structure progressively disappear during adsorption of hydrogen, suggesting the formation of a disordered structure. During the first 20 ps of time equilibration (Figure 3a, configuration C), combination of atomic hydrogen and desorption of $\mathrm{H}_{2}$ molecules occur at the surface of the $\mathrm{Au} \mathrm{NP}$ and the number of adsorbed atomic hydrogen reduces to 102, i.e., to 0.8 ML. The configuration $\mathrm{C}$ shows the initial stage of formation of several $\mathrm{H}-\mathrm{Au}-\mathrm{H}-\mathrm{Au}$ chains on the surface of the Au NP, with one hydrogen bridging two gold atoms. After 60 ps time span, well-organized long H-Au-H-Au crown lines are stabilized (Figure 3a, configuration D). They are found to continuously slide all around a highly distorted gold core. Interestingly, HAADFSTEM simulation of the selected hydrogenated MD structures at 0, 20, 40, 60 ps (Figure 3c) gives rise to image contrast similar to the ones observed experimentally (Figure 2e-1). These MD simulation results thus highly support the experimentally-observed structural changes in Au NPs smaller than $\sim 4 \mathrm{~nm}$.

Further analysis of the dynamic behavior of individual atoms during the simulation time reveals strong structural fluctuations with $\mathrm{Au}-\mathrm{Au}$ bond breaking and formation of new $\mathrm{Au}-\mathrm{Au}$ and $\mathrm{Au}-\mathrm{H}$ bonds (Figure S6, Supporting Information). This Figure shows the relative motion between atoms monitored by following the separation of $\mathrm{Au}-\mathrm{Au}$ and $\mathrm{Au}-\mathrm{H}$ atom pairs at the particle surface (i.e. at the crown chains) and of $\mathrm{Au}-\mathrm{Au}$ atom pairs in its core (i.e. in the inner 
shell and in the center of 19 atoms) during time simulation. While highly mobile gold and hydrogen atoms at the surface reach the stage of bond retention after 40 ps corresponding to the formation of well-ordered $\mathrm{H}-\mathrm{Au}-\mathrm{H}-\mathrm{Au}$ crown chains in configuration $\mathrm{D}$, the $\mathrm{Au}-\mathrm{Au}$ bond breaking and re-formation still proceed after 60 ps simulation time span for gold atoms in the particle center. These simulated structural fluctuations are in agreement with the strong structural instability observed in the gold nanoparticles presented in (Figure 1c and Video S1, Supporting Information) Similar results are obtained for the MD simulations performed at room temperature. 


\section{a}
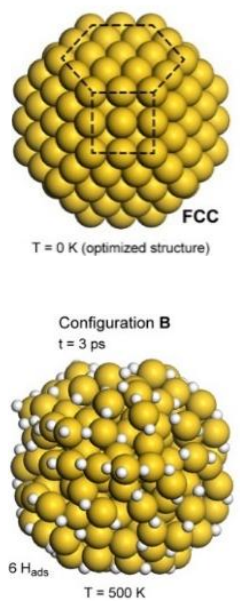
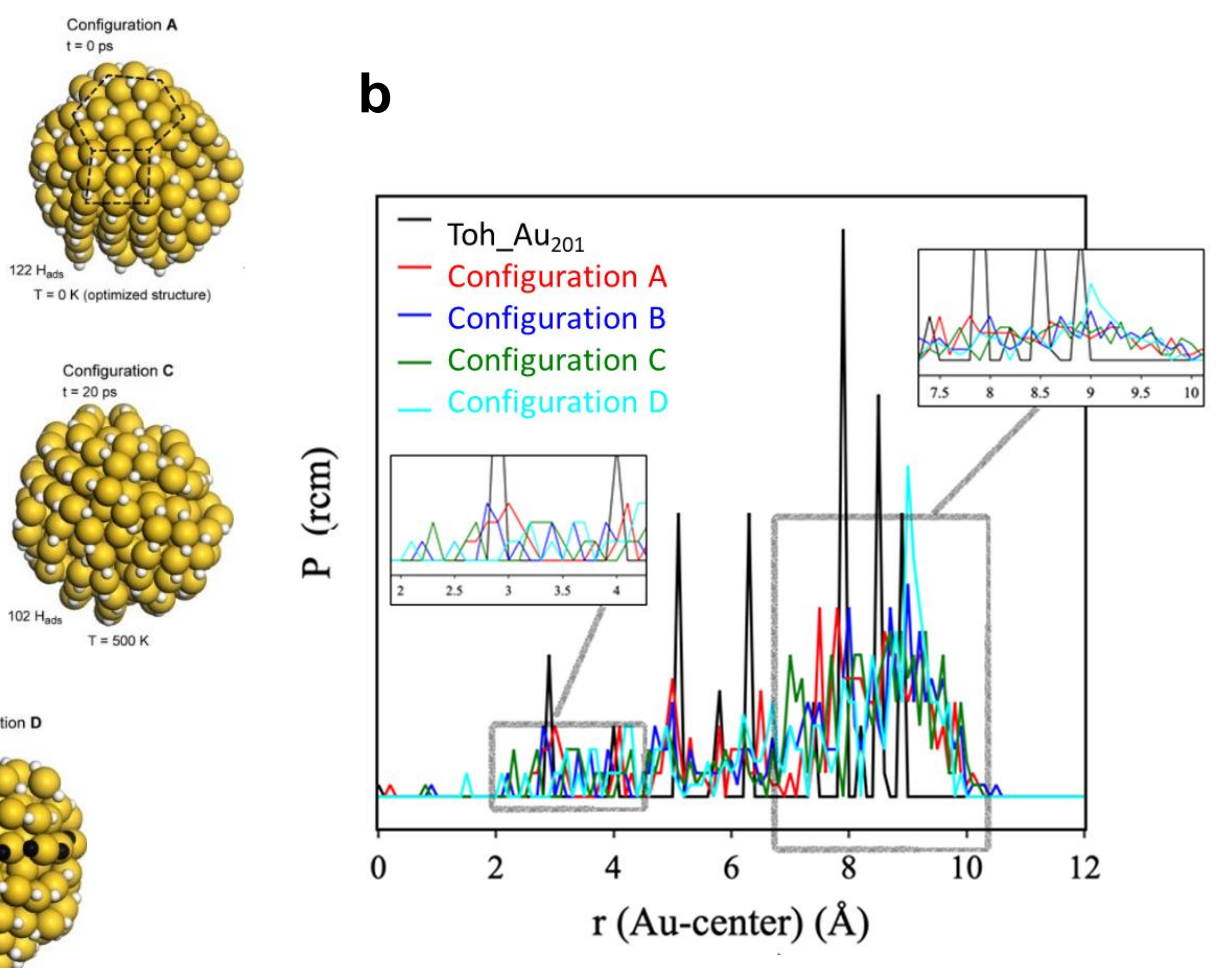

b

C
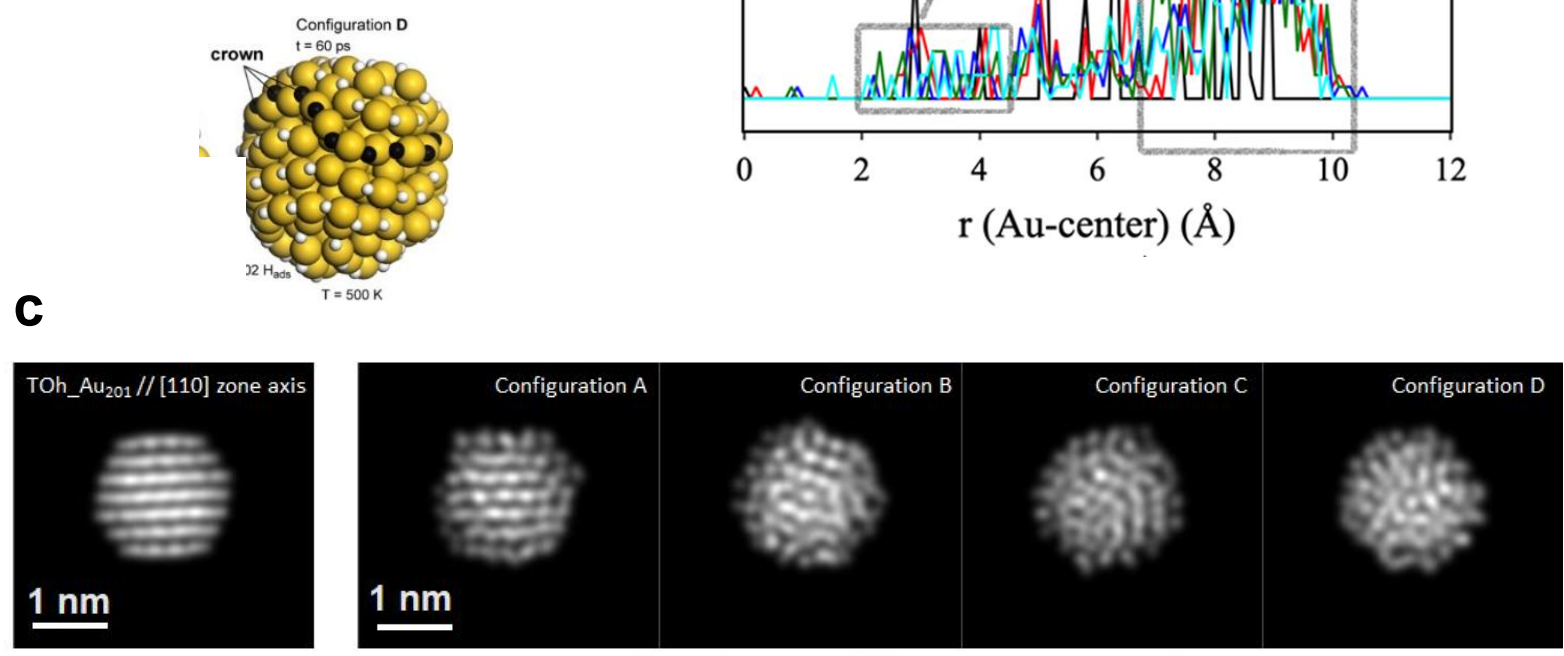

d

Structure evolution of TOh_Au $\mathrm{Au}_{201} \mathrm{H}_{122} / /[110]$ zone axis during MD simulations

Configuration D'

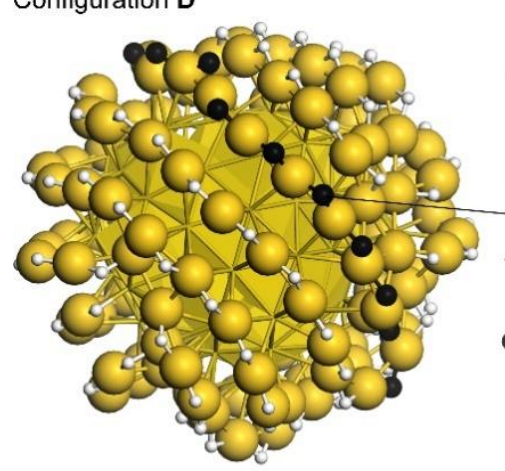

$\mathrm{T}=0 \mathrm{~K}$ (optimized structure)

$126 \mathrm{Au}$ (surface); $75 \mathrm{Au}$ (core); $102 \mathrm{H}_{\text {ads }}$

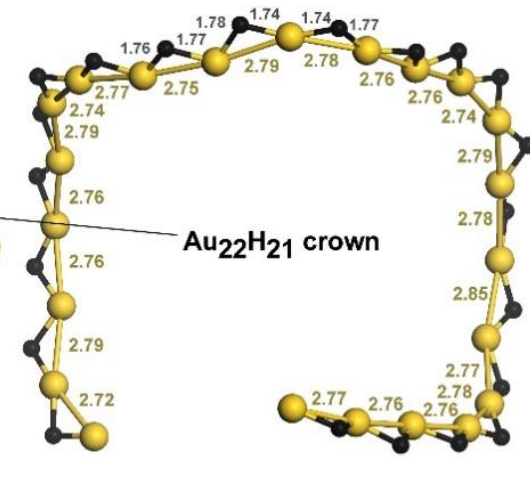

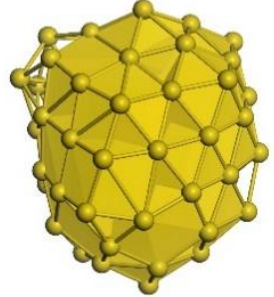

Au core : 75 atoms Au center: 19 atoms (inner shell+center) (icosahedral-like symmetry)

Figure 3. Ab initio molecular-dynamics (AIMD) simulations of model gold NP in presence of hydrogen and DFT optimized structure. a) Optimized structure of $\mathrm{TOh} \_\mathrm{Au}_{201}$ with fcc structure. Different configurations extracted from the AIMD simulation at $500 \mathrm{~K}$ of $\mathrm{TOh} \_\mathrm{Au}_{201}$ covered by adsorbed hydrogen atoms: Configuration A $(t=0)$ obtained after DFT geometry optimization (at $0 \mathrm{~K}$ ) of TOh_Au $\mathrm{Au}_{201} \mathrm{H}_{122}$. Configuration $\mathrm{B}(\mathrm{t}=3 \mathrm{ps}$ ) corresponding to the earlier stage of structural change process. Configuration $\mathrm{C}(\mathrm{t}=20 \mathrm{ps})$ obtained after thermal equilibration, with 116 adsorbed $\mathrm{H}$ atoms and 3 desorbed $\mathrm{H}_{2}$ molecules in the gas phase. Configuration $\mathrm{D}(\mathrm{t}=60$ ps) with well-formed linear chains on the surface, 102 adsorbed $\mathrm{H}$ atoms and 10 desorbed $\mathrm{H}_{2}$ molecules. Color 
code of the spheres: Au (yellow), H (white). To facilitate the visualization, hydrogen atoms belonging to onecrown line are represented in black small spheres. b) The probability distribution functions $\mathrm{P}(\mathrm{rcm}) \mathrm{of}$ the $\mathrm{Au}$ atoms relative to the center of mass in DFT optimized TOh_Au $\mathrm{Au}_{201}$ and in configurations $\mathrm{A}, \mathrm{B}$ and C. The enlarged windows show $\mathrm{P}(\mathrm{rcm})$ at the core and near the surface. c) HAADF simulations of TOh_Au $\mathrm{Au}_{201}$ and the selected configurations A, B, C and D. d) From the left to the right: D' configuration obtained after DFT optimization of configuration D (extracted from the AIMD trajectory); one on the formed $\mathrm{H}-\mathrm{Au}-\mathrm{H}-\mathrm{Au}$ surface crown line (The indicated values are in Angstrom); the distorted structure of the core (75 Au atoms) and the icosahedral-like Au structure of the center (19 atoms).

When configuration D is quenched at $0 \mathrm{~K}$ and its geometry is optimized by DFT, we identify an ordered $\mathrm{H}-\mathrm{Au}-\mathrm{H}-\mathrm{Au}$ crown structures consisting of repetitive $\mathrm{H}$ bridging Au motifs with near-constant $\mathrm{Au}-\mathrm{Au}$ and $\mathrm{Au}-\mathrm{H}$ distances at the nanoparticle surface (Figure 3d, Configuration D'). The $\mathrm{H}-\mathrm{Au}-\mathrm{H}-\mathrm{Au}$ crown lines decorating the Au NP involve all surface atoms, i.e. $60 \%$ of the total atom number. This ordered surface molecular structure might provide distinct catalytic properties to the hydrogenated NPs that are different from what we can find in the literature from studies considering flat $\mathrm{Au}$ surfaces or perfect crystal forms as model catalysts. In addition to the evidenced geometric ensemble effect where all gold surface atoms are henceforth lower coordinated sites, the electronic structure of the gold NP surface sites is unique. This is primary illustrated by the distribution of charge density at the NP surface depicted in (Figure 4a) showing a strong accumulation of electron density over the $\mathrm{Au}-\mathrm{H}-\mathrm{Au}$ crown lines and a strong depletion in between (The inner shell atoms). The Bader charge calculations show that the Au atoms of the crown lines have larger negative charges ( $>0.04 \mathrm{e}$, with e the elementary charge) than those from the inner shell which are almost positive (see enlarged part in Figure 4a). This suggests that the surface restructuration may offer two types of accessible $\mathrm{Au}$ sites for reactants and intermediates of hydrogenation catalytic reactions.

Finally, the analysis of the structure of the NP core shows important atomic ordering changes with surface segregation of bulk Au atoms resulting in a strongly disordered inner shell and a 
highly distorted icosahedral-like center (Figure 3d). The latter recalls the icosahedral structures observed experimentally (Figure 1b). These results elucidate how hydrogen adsorption induces fcc to icosahedral-like structural transformations in Au NPs observed by in situ TEM. They are in excellent agreement with the reported classical MD results of $\mathrm{H}$. Ogawa predicting the possible transformation from fcc to icosahedral arrangements for a given hydrogenated fcc metal nanoparticle smaller than $2 \mathrm{~nm} \cdot{ }^{[30]}$ This author also reported that this strong disorder and lattice deformations might occur if the $\mathrm{M}-\mathrm{H}$ interactions are strong enough. In our work, the adsorption of atomic hydrogen is found to stabilize at $0.8 \mathrm{ML}$ coverage with adsorption energy of $-0.025 \mathrm{eV} / \mathrm{H}$. This value is higher than the calculated adsorption energies on flat gold surfaces or perfect crystal NPs,${ }^{[31,32,33,34]}$ but is fully consistent with experimental experimental works predicting the dissociative chemisorption of $\mathrm{H}_{2}$ on gold catalyst $^{[10,28,35,36,37]}$ for temperature in the range of $298-523 \mathrm{~K}^{[10]}$ providing by the way, a rational explanation of the observed structural transformations. The predicted strong hydrogen adsorption governing the structural changes is also illustrated by the drastic changes in the $\mathrm{Au}$ $5 d$-band density of states of $\mathrm{Au}$ atoms from both the surface and the center in configuration D' compared to bare TOh_Au $\mathrm{Au}_{201} \mathrm{NP}$. Figure $4 \mathrm{~b}$ and $4 \mathrm{c}$ show that, while the occupied orbitals of the hydrogenated surface gold atoms downshift away from the Fermi level as expected upon hydrogen chemisorption, those of the center atoms upshift toward lower energies, signature of charge transfers for the benefit of the upper surface atoms. In addition, the narrowing of the $d$-band density of state of the center $\mathrm{Au}$ atoms (19 atoms) found for configuration D' compared to $\mathrm{TOh}_{-} \mathrm{Au}_{201}$ is in complete agreement with the theoretically predicted and experimentally observed transition from fcc to icosahedral-like symmetry. ${ }^{[38]}$ All these results open the way for a deep investigations of the reactivity of these revealed surface active sites to understand the "real" reaction mechanisms occurring over hydrogenated gold nanocatalyst. 

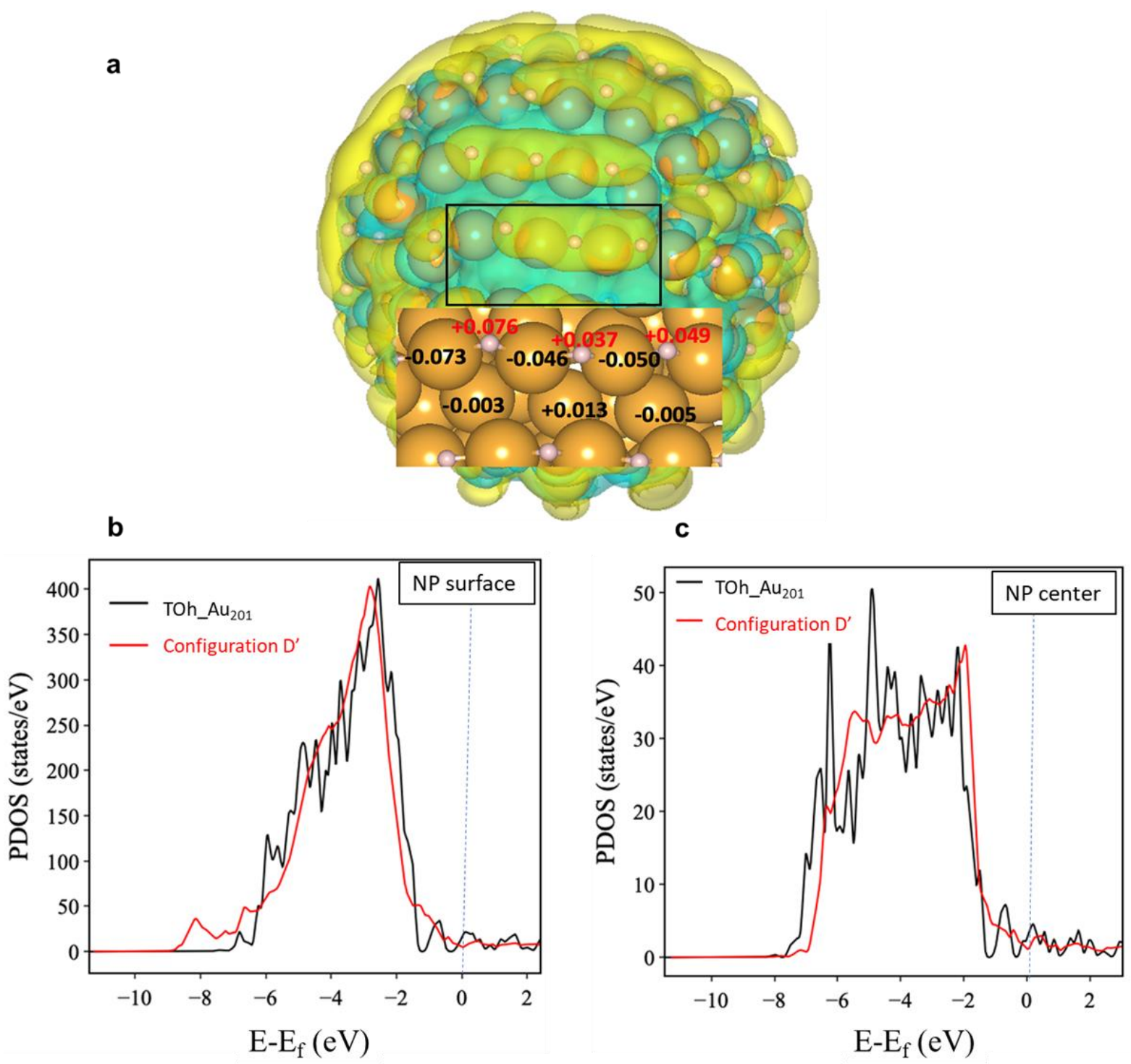

Figure 4. Electronic structure analyses of the optimized DFT structure (D') of hydrogenated Au NP. a) 3D charge-density difference on configuration $\mathrm{D}^{\prime}$ with an isosurface value of $0.00015 \mathrm{e} / \mathrm{bohr}^{3}$. Color code: yellow, gaining electrons; blue, losing electrons. The inset reports the Bader charges of a selected region where red and black values are for hydrogen and gold atoms, respectively. b,c) Au $5 d$-band density of states of the surface crown lines (a) and of the center (19 atoms) (b) calculated from D' configuration (red curves) and compared with initial non hydrogenated gold NP, TOh_Au ${ }_{201}$ (black curves). The $d$-band centers of surface atoms from hydrogenated and non-hydrogenated Au NP are calculated to be of $-3.33 \mathrm{eV}$ and $-3.20 \mathrm{eV}$, respectively. The dband centers of center atoms (19 atoms) from hydrogenated (icosahedral-like) and non-hydrogenated (fcc symmetry) Au NP are calculated to be of $-3.47 \mathrm{eV}$ and $-3.72 \mathrm{eV}$, respectively. $E_{\mathrm{f}}$ is the Fermi energy.

\section{Conclusion}

In conclusion, using environmental transmission electron microscopy, we provide the first real space evidence of the size dependent structural evolution on Au NPs under hydrogen. We 
reveal symmetry transformations from fcc to icosahedral-like or other undefined structures occurring in Au NP with size below $4 \mathrm{~nm}$. Performing AIMD simulations, we demonstrate that these structural evolutions resulting from the high mobility of gold atoms are induced by strong $\mathrm{Au}-\mathrm{H}$ interactions and we bring insights into the unique atomic and electronic structure of the interfacial sites of Au NPs and hydrogen in this critical size regime. This work recalls the necessity of considering the adsorption-inducing restructuration to explain the sizedependent catalytic activity of gold nanocatalysts. It shows that the idea of low coordinated surface atoms at particle edges and corners as the main active sites is incomplete and that in addition, ensemble and electronic effects induced by the surface and core restructuration have to be considered. This work also opens the question of the mechanistic origins of the structural flexibility of Au NPs under reactive gas as a key point for the understanding and the optimization of active gold-based heterogeneous nanocatalysts.

\section{Experimental Section}

Sample preparation: A titania-supported gold catalysts $\left(\mathrm{Au} / \mathrm{TiO}_{2}\right.$ with 6 wt $\left.\% \mathrm{Au}\right)$ sample was prepared by deposition-precipitation technique in the presence of urea. This preparation method produces gold NPs with average size around 3-4 $\mathrm{nm}$ and catalytically active in selective hydrogenation reactions. ${ }^{[39,40]}$ The range of Au particle sizes studied in this work is typically the one encountered in the literature for active gold catalysts in various oxidation or hydrogenation catalytic reactions. ${ }^{[18]}$ Moreover, experimental limitations resulting from electron scattering by the silicon nitride windows of the high-pressure gas cell, and STEM contrast from the $\mathrm{TiO}_{2}$ support, it was not possible to resolve the atomic structure of Au NPs smaller than $\sim 3 \mathrm{~nm}$. As support, a commercial $\mathrm{TiO}_{2}(100 \%$ anatase, US research nanomaterials, surface area $50 \mathrm{~m}^{2} \cdot \mathrm{g}^{-1}$, purity $=99.98 \%$ ) was used. First, a suspension of $\mathrm{TiO}_{2}$ $(2 \mathrm{~g})$ in distilled water $(150 \mathrm{ml})$ was prepared in a double wall-reactor. The solution was 
stirred and heated in order to well disperse the support up to $80{ }^{\circ} \mathrm{C}$. Then, an appropriate quantity $(27.5 \mathrm{~mL})$ of a solution of gold precursor $\mathrm{HAuCl}_{4} .3 \mathrm{H}_{2} \mathrm{O}$ (Sigma-Aldrich, 4.5 g.L $\mathrm{L}^{-1}$ ) to achieve Au loading of $6 \mathrm{wt} \%$, was added to the $\mathrm{TiO}_{2}$ suspension. Instantly, urea $\mathrm{CO}\left(\mathrm{NH}_{2}\right)^{2}$ (Sigma-Aldrich) was also added in excess $([$ urea $] /[$ metal $]=100)$. The mixture at $80{ }^{\circ} \mathrm{C}$ was then stirred 20 hours in the dark to avoid uncontrolled reduction of gold. The obtained solid was then separated from the liquid phase by centrifugation. After centrifugation, the solid was washed three times with distilled water to remove impurities, in particular residual chlorides. The sample was then dried under vacuum, in dark and at room temperature for 24 hours. The $\mathrm{Au}$ gold loading determined by X-ray fluorescence was 5.8 wt $\%$. The catalyst was then activated in a fixed bed microreactor in Pyrex (home-built, $4 \mathrm{~mm}$ of internal diameter), leading to the so-called as-prepared $\mathrm{Au} / \mathrm{TiO}_{2}$., i.e. gold was reduced into metal particles, by temperature-programmed reduction (ramp $2{ }^{\circ} \mathrm{C} \cdot \mathrm{min}^{-1}$ ) under flow of $\mathrm{H}_{2}$ (Air Liquide, purity $99.999 \%),\left(100 \mathrm{ml} \cdot \mathrm{min}^{-1}\right)$ from RT to $300{ }^{\circ} \mathrm{C}$ then maintained at $300{ }^{\circ} \mathrm{C}$ for 2 hours of pure hydrogen. The microreactor was then purged with $\mathrm{N}_{2}$ (Air Liquide, purity $99.999 \%$ ) before exposure to air. The same sample batch of as-prepared $\mathrm{Au} / \mathrm{TiO}_{2}$ was used for all the experiments presented in this work.

In situ environmental TEM: All electron microscopy observations were carried out in double aberration-corrected JEOL ARM 200F microscope equipped with a cold field emission gun operated at $200 \mathrm{kV}$. For in situ STEM observations in gas phase, a Protochips Atmosphere ${ }^{\mathrm{TM}}$ TEM environmental high-pressure gas cell (HPGC) was used. It consists of a pair of silicon microchips (called E-chips) aligned and assembled in closed-cell configuration at the tip of a dedicated TEM sample holder. The small E-chip is a $2 \mathrm{~mm} \times 2 \mathrm{~mm}, 300 \mu \mathrm{m}$-thick silicon chip with a $300 \mu \mathrm{m} \times 300 \mu \mathrm{m} 50 \mathrm{~nm}$-thick amorphous SiN window at its center. As for the large Echip, it is a $6.0 \mathrm{~mm} \times 4.5 \mathrm{~mm}$ and $300 \mu \mathrm{m}$-thick Si microchip with a $300 \mu \mathrm{m} \times 300 \mu \mathrm{m} \mathrm{SiC}$ membrane at its center. The SiC film is patterned with six (2 lines of 3) $7 \mu \mathrm{m}$ in diameter 
circular windows made up of $30 \mathrm{~nm}$ thick amorphous $\mathrm{SiN}$. The as-prepared $\mathrm{Au} / \mathrm{TiO}_{2}$ sample were deposited on the large E-chip by drop casting $6 \mu \mathrm{l}$ of a suspension of Au NPs ultrasonically dispersed in distilled water. TEM observations were carried out through these electron-transparent windows. The Au NPs were subjected to pure argon (Messer, purity > $99.999 \%$ ) and pure hydrogen (Messer, purity > $99.999 \%$ ) in static gas conditions using a manually-operated gas manifold from Protochips. Gas pressure in the HPGC cell was controlled using a MKS PDR 2000 dual capacitance manometer. The nominal gas layer thickness was $5 \mu \mathrm{m}$ fixed by gold spacers patterned on the E-chips HPGC. The sample was heated through resistive heating of the $\mathrm{SiC}$ membrane via current injection using an electronic control unit interfaced with Protochips Aduro 300 software with closed-loop temperature control. For the latter, the software uses chip-specific ohmic resistance of the SiC film versus temperature calibration files as input. Gold NPs were imaged in STEM mode, using both the HAADF and BF detectors. The probe setting used for image acquisition was $8 \mathrm{C}$ and the convergence semi-angle was set to $20.5 \mathrm{mrad}$ (by using a $40 \mu \mathrm{m}$ condenser lens). The resulting probe size was $0.7-0.8 \AA$ and the corresponding probe current was close to $27 \mathrm{pA}$ (both quantities being measured in vacuum). The camera lens was set to $8 \mathrm{~cm}$ corresponding respectively to inner and outer collection semi-angles of 68 and $280 \mathrm{mrad}$ for HAADF imaging. For BF imaging, the collection semi-angle was limited to $17 \mathrm{mrad}$ by using a $3 \mathrm{~mm}$ BF aperture. High-resolution STEM images $(2048 \times 2048$ pixels $)$ were acquired at magnifications of $\times 10 \mathrm{M}$ and $\times 20 \mathrm{M}$ (figure $1 \mathrm{~b}$ and $\mathrm{c}$ only) with pixel area equal to $8.97 \times 10^{-}$ ${ }^{3}$ and $2.24 \times 10^{-3} \AA^{2}$ respectively. To limit the effect of the electron beam during in situ STEM imaging, all images were captured with a limited acquisition time of 2 or $3 \mu$ s per pixel and the electron illumination was blanked between image acquisition. Under these acquisition conditions, the dose per frame, as defined in ${ }^{[41]}$ was equal to $3.76 \times 10^{10}$ or $5.64 \times 10^{10}$ e $\AA^{-2}$ at $\times$ 
$10 \mathrm{M}$ magnification and was raised to $1.51 \times 10^{11}$ or $2.26 \times 10^{11}$ e $\AA^{-2}$ at $\times 20 \mathrm{M}$ magnification. The same doses per frame were selected for ex situ STEM observation.

Ex situ STEM: Ex situ observations of the as-prepared $\mathrm{Au} / \mathrm{TiO}_{2}$ catalyst was carried out under static atmospheric pressure of pure hydrogen (Air Liquide, purity $99.999 \%$ ) in the home-built fixed bed microreactor in Pyrex. The catalyst $(15 \mathrm{mg})$ was heated from room temperature to $400{ }^{\circ} \mathrm{C}\left(\operatorname{ramp} 10{ }^{\circ} \mathrm{C} \cdot \mathrm{min}^{-1}\right)$ under $\mathrm{H}_{2}$, held for $1 \mathrm{~h}$ at this temperature, then cooled to $200{ }^{\circ} \mathrm{C}\left(\operatorname{ramp~} 10{ }^{\circ} \mathrm{C} \cdot \mathrm{min}^{-1}\right)$ and maintained for $1 \mathrm{~h}$ at $200{ }^{\circ} \mathrm{C}$ before cooling to room temperature. After heating, the microreactor was purged with $\mathrm{N}_{2}$ (Air Liquide, purity 99.999\%) before exposure to air. The pressure and temperature conditions under hydrogen were chosen to be consistent with those applied during in situ TEM observations. The $\mathrm{H}_{2}$ treated $\mathrm{Au} / \mathrm{TiO}_{2}$ catalyst was then recovered and transferred in air for high resolution ex situ STEM observations at room temperature and under vacuum $\left(\sim 10^{-6} \mathrm{~Pa}\right)$. The sample for electron microscopy was prepared by dispersing the hydrogen-exposed catalyst in distilled water and depositing 10 drops of $2 \mu \mathrm{l}$ of the resulting solution onto a holey carbon-coated copper TEM grid (Agar Scientific). For STEM imaging, the illumination and image acquisition conditions were similar to those set for in situ STEM.

STEM simulation: Atomically-resolved HAADF STEM image simulation was performed with the STEM simulation software developed by He, Li and Yuan using Matlab 7.12.0.635 (R2011a). ${ }^{[42]}$ This software assumes kinetic scattering of the electrons (i.e. the incident electrons are only scattered once) by the atoms of the structure under consideration. Within this approximation, which holds for atomic columns with less than 10-50 atoms, the integrated HAADF intensity at each point of scan is proportional to the total number of atoms encountered by the incident electron along its propagation path. The Gaussian width that describes the effective width of the electron probe was set to $0.7 \AA$ in all simulations to match the spatial resolution of the JEOL ARM 200F microscope under the selected illumination 
conditions. Another important simulation parameter is the exponent power (also denoted as the Exponent number in the software) which describes the dependency of the HAADF intensity with the atomic number. Its value varies with the inner acceptance angle of the HAADF detector as shown in. ${ }^{[43]}$ Based on the selected collection conditions, its value was fixed to 1.7 in all simulations. Atomic structure models used as inputs of STEM simulations were either taken from the simulation software database (bare 931-atom icosahedron in Figure S5, Supporting information) or extracted from AIMD simulations of the 201-atom Au NP with 1 ML coverage of hydrogen (simulated atomic structures in Figure 3).

Cluster model: Regular truncated octahedron of $1.8 \mathrm{~nm}$ size composed by $201 \mathrm{Au}$ atoms $\left(\mathrm{TOh} \_\mathrm{Au}_{201}\right)$ was considered. ${ }^{[44]}$ This size is representative of gold nanoparticles undergoing structural transformations under hydrogen in our TEM observations. To account for the presence of atmospheric hydrogen pressure, the hydrogen coverage was fixed to $1 \mathrm{ML}$, which corresponds to the adsorption of $122 \mathrm{H}$ atoms (TOh-Au201-H122). The gold NP model structures were modeled using a cubic cell of dimensions $(30 \times 30 \times 30) \AA^{3}$. The NP models for MD simulations ( $\mathrm{TOh} \_\mathrm{Au}_{201}$ and $\mathrm{TOh} \_\mathrm{Au}_{201} \mathrm{H}_{122}$ noted configuration $\mathrm{A}$ in Figure $3 \mathrm{a}$ ) were initially optimized by DFT calculations, leading to fcc local minimum energy structures with slightly distorted surface facets, for the case of hydrogen adsorption with $\mathrm{H}$ atoms mainly occupying twofold bridge and threefold hollow sites.

AIMD simulations and DFT calculations: Ab Initio Molecular Dynamics simulations involving Born-Oppenheimer approximation were performed in the canonical (NVT) ensemble employing Nosé-Hoover thermostat with a time step of 1.5 fs at $300 \mathrm{~K}$ and $500 \mathrm{~K}$ with a total integration time of 60 ps. ${ }^{[45,46]}$ All ab initio MD simulations and DFT calculations were conducted using Vienna ab initio Simulation Package (VASP 541). ${ }^{[47,48]}$ All local minima associated with specific atomic arrangements selected from MD simulations were isolated and their geometrical and electronic properties were calculated and analyzed by DFT 
method. The Generalized Gradient Approximation functional of the exchange-correlation energy was calculated within the Perdew, Burke, and Ernzerhof formulation of the generalized-gradient approximation (GGA-PBE). ${ }^{[49,50]}$ Van der Waals interactions have been considered for all the models throughout the DFT study by selecting the dispersion corrected PBE-D3 functional proposed by Grimme. ${ }^{[51]}$ The cut off energy was fixed to $400 \mathrm{eV}$. Fine geometry optimizations were performed by choosing a convergence threshold of $10^{-6} \mathrm{eV}$ for the total electronic energy and a threshold of $\pm 10^{-2} \mathrm{eV} \cdot \AA^{-1}$ for minimizing residual forces acting on the nuclei. In order to describe the interaction between gold nanoparticle and atomic hydrogen, the adsorption energy normalized by the number of $\mathrm{H}$ atoms (N_Hads) was defined as follows:

$$
\Delta \text { Eads }=(\mathrm{E}(\mathrm{TOh}+\text { adsorbate })-\mathrm{E}(\mathrm{TOh})-\mathrm{E}(\text { adsorbate })) / \mathrm{N}_{-} \mathrm{H}_{\mathrm{ads}},
$$

where $\mathrm{E}(\mathrm{TOh}+$ adsorbate), $\mathrm{E}(\mathrm{slab}), \mathrm{E}($ adsorbate) are the calculated electronic energy of $\mathrm{H}$ species adsorbed on the gold nanoparticle, of bare TOh nanoparticle, of gas phase $\mathrm{H}_{2}$, respectively. The adsorption energy per $\mathrm{H}$ atom referres to $1 / 2 \mathrm{H}_{2}(\mathrm{~g})$.

\section{Supporting Information}

Supporting Information is available from the Wiley Online Library or from the author.

\section{Acknowledgements}

This work was supported by the French National Research Agency through the TOTEM project, Grant Number ANR-17- CE07-0031. A. N was supported by a PhD fellowship granted through the same project. The authors are grateful to Region Ile de France for convention SESAME E1845 for the support of the JEOL electron microscope installed at 
Université de Paris. The authors thank IDRIS in Paris, CINES in Montpellier, TGCC in Grenoble (project 609 and A0090807369, GENCI/CT8) and especially PSMN in Lyon for CPU time and assistance. The authors thank the CPER/SYSPROD 2015-2022 project (N²019-AURA-P5B) and AXELERA Pôle de Compétitivité (PSMN Data Center). The authors are also grateful to GDR Or-Nano (GDR n ${ }^{\circ}$ 2002) for his work to stimulate effective collaborations.

A. N and Q. W contributed equally to this work.

Received: XXXX

Revised: XXXX

Published online: XXXX

\section{References}

[1] G. C. Bond, P. A. Sermon, G. Webb, D. A. Buchanan, P. B. Wells, J. Chem. Soc. Chem. Commun. 1973, 13, 444b-445.

[2] C. Mohr, P. Claus, Science Progress 2001, 84, 311-334.

[3] T. Ishida, T. Murayama, A. Taketoshi, M. Haruta, Chem. Rev. 2019, 120, 464-525.

[4] G. C. Bond, Gold Bull. 2016, 49, 53-61.

[5] G. C. Bond, Faraday Discuss. 2011, 152, 277-291.

[6] G. C. Bond, D. T. Thompson, Catal. Rev. 1999, 41, 319-388.

[7] D. Astruc, Nanoparticles and Catalysis Ch. 15, John Wiley and Sons, Weinheim 2008.

[8] A. K. Gatin, M. V. Grishin, N. V. Dokhlikova, N. N. Kolchenko, B. R. Shub, Doklady Physical Chemistry 2016, 470, 125-128.

[9] M. Wijzenbroek, D. Helstone, J. Meyer, G. J. Kroes, J. Chem. Phys. 2016, 145, 144701. 
[10] E. Bus, J. T. Miller, J. A. Van Bokhoven, J. Phys. Chem. 2005, 109, 14581-14587.

[11] A. Hugon, L. Delannoy, C. Louis, Gold Bull. 2008, 41, 127-138.

[12] R. Meyer, C. Lemire, S. K. Shaikhutdinov, H. J. Freund, Gold Bull. 2004, 37, 72-124.

[13] K. Ueda, Y. Kawasaki, H. Hasegawa, T. Tanji, M. Ichihashi, Surf. Interface Anal. 2008, $40,1725-1727$.

[14] A. Howie, Faraday Discuss. 1991, 92, 1-11.

[15] A. Chmielewski, J. Meng, B. Zhu, Y. Gao, H. Guesmi, H. Prunier, D. Alloyeau, G. Wang, C. Louis, L. Delannoy, P. Afanasiev, C. Ricolleau, J. Nelayah, ACS Nano 2019, 13, 2024-2033.

[16] W. P. Halperin, Rev. of Modern Physics 1986, 58, 533-607.

[17] A. Roldan, S. Gonzalez, J. M. Ricart, F. Illas, ChemPhysChem 2009, 10(2), 348-351.

[18] G. C. Bond, C. Louis, D. Thompson, Catalysis by Gold, Imperial College Press, 2006.

[19] M. Arenz, U. Landman, U. Heiz, ChemPhysChem 2006, 7(9), 1871-1879.

[20] B. Zandkarimi, P. Poths, A. N. Alexandrova, Angew. Chem. Int. Ed. 2021, 60, $11973-$ 11982.

[21] A. Vargas, G. Santarossa, M. Iannuzzi, A. Baiker, Phys. Rev. B 2009, 80, 195421

[22] P. L. Hansen, J. B. Wagner, S. Helveg, J. R. Rostrup-Nielsen, B. S. Clausen, H. Topsoe, Science 2002, 295(5562), 2053-2055.

[23] F. Ye, M. Xu, S. Dai, P. Tieu, X. Ren, X. Pan, Catalyst 2020, 10(7), 779-799

[24] W. Yuan, B. Zhu, K. Fang, T. W. Hansen, Y. Ou, H. Yang J. B. Wagner, Y. Gao, Y. Wang, Z. Zhang, Science 2021, 371(6528), 517-521.

[25] Y. He, J. C. Liu, L. Luo, Y. G. Wang, J. Zhu, Y. Du, J. Li, S. X. Mao, C. Wang, PNAS. 2018, 115, 7700-7705.

[26] A. Corma, M. Boronat, S. González, F. Illas, Chem. Commun. 2007, 32, 3371-3373. 
[27] P. A. Ferrin, S. Kandoi, J. Zhnag, R. Adzic, M. Mavrikakis, J. Phys. Chem. C. 2009, 113, $1411-1417$

[28] M. Boronat, P. Concepción, A. Corma, J. Phys. Chem. C. 2009, 113, 16772-16784.

[29] S. Giorgio, M. Cabié, C. R. Henry, Gold Bull. 2008, 41, 167-173.

[30] H. Ogawa, Mater. Trans. 2011, 52, 614-617.

[31] J. J. Determan, S. Moncho, E. N. Brothers, B. G. Janesko, J. Phys. Chem. C. 2014, 118, $15693-15704$.

[32] K. E. Batista, J. L. Da Silva, M. J. Piotrowski, J. Phys. Chem. C. 2019, 123, 7431-7439.

[33] M. Wijzenbroek, D. Helstone, J. Meyer, G. J. Kroes, J. Chem. Phys. 2016, 145, 144701.

[34] A. K. Gatin, M. V. Grishin, N. V. Dokhlikova, N. N. Kolchenko, B. R. Shub, Dokl. Phys. Chem. 2016, 470, 125-128.

[35] A. C. Gluhoi, H. S.Vreeburg, J. W. Bakker, B. E. Nieuwenhuys, Appl. Catal. A. Gen. 2005, 291(1-2), 145-150.

[36] M. Boronat, F. Illas, A. Corma, J. Phys. Chem. A 2009, 113(16), 3750-3757.

[37] E. Bus, J. A. van Bokhoven, Phys. Chem. Chem. Phys. 2007, 9(22), 2894-2902.

[38] C. Mottet, G. Tréglia, B. Legrand, Surf. Sci. 1996, 352, 675-679.

[39] R. Zanella, L. Delannoy, C. Louis, Appl. Catal. A. Gen. 2005, 291, 62-72.

[40] L. Delannoy, G. Thrimurthulu, P. S. Reddy, C. Méthivier, J. Nelayah, B. M. Reddy, C. Ricolleau, C. Louis, Phys. Chem. Chem. Phys. 2014, 16, 26514-26527.

[41] P. Abellan, T. J. Woehl, L. R. Parent, N. D. Browning, J. E. Evans, I. Arslan, Chem. Comm. 2014, 50, 4873-4880.

[42] D. S. He, Z. Y. Li, J. Yuan, Micron 2015, 74, 47-53.

[43] Z. W. Wang, Z. Y. Li, S. J. Park, A. Abdela, D. Tang, R. E. Palmer, Phys. Rev. B. 2011, $84,073408$. 
[44] C. H. Chan, F. Poignant, M. Beuve, E. Dumont, D. Loffreda, J. Phys. Chem. Lett. 2019, 10, 1092-1098.

[45] W. G. Hoover, Phys. Rev. A. 1985, 31, 1695.

[46] S. Nosé, J. Chem. Phys. 1984, 81, 511-519.

[47] G. Kresse, J. Hafner, Phys. Rev. B. 1993, 47, 558.

[48] G. Kresse, J. Furthmüller, Phys. Rev. B. 1996, 54, 11169.

[49] J. P. Perdew, K. Burke, M. Ernzerhof, Phys. Rev. Lett. 1996, 77, 3865.

[50] J. P. Perdew, J. A. Chevary, S. H. Vosko, K. A. Jackson, M. R. Pederson, D. J. Singh, C. Fiolhais, Phys. Rev. B. 1992, 46, 6671.

[51] S. Grimme, J. Antony, S. Ehrlich, H. A. Krieg, J. Chem. Phys. 2010, 132, 154104.

\section{Table of Contents Text}

Atomic-resolution transmission electron microscopy reveals size-dependent structural transformations in supported gold nanoparticles upon exposure hydrogen at atmospheric pressure. Molecular dynamics simulations calculations highlight the role of mobile gold atoms in the evolution of particle crystal structure and morphology observed below $4 \mathrm{~nm}$ and unveil the unique atomic and electronic structures of hydrogenated gold nanoparticles in this critical size regime.

\section{Table of Contents Figure}

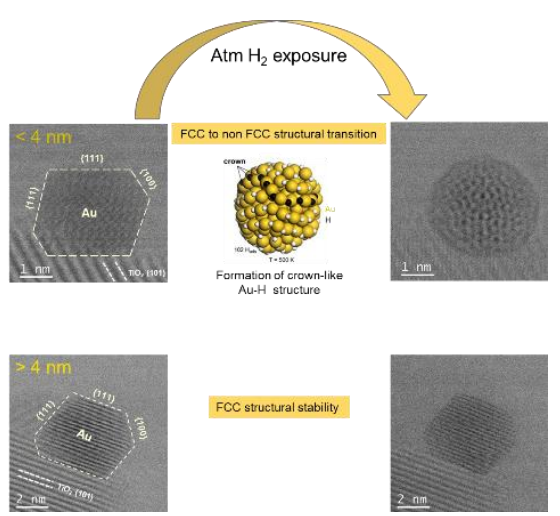




\section{Supporting Information}

Supporting Information is available from the Wiley Online Library or from the author.

\section{Conflict of Interest}

The authors declare no conflict of interest.

\section{Data Availability Statement}

The ETEM data and STEM simulations that support the main findings of this study are properties of the Quantum Materials and Phenomena laboratory of Université de Paris. They are available from the corresponding author J. N on request. All DFT and MD simulation results are also available from the corresponding authors H.G and D. L. on request.

\section{Author Informations}

These authors contribute equally: Abdallah Nassereddine, Qing Wang

J. N, H. G and D. L conceived the ideas. A.N, L.D and C.L fabricated the samples. A.N and J.N performed the electron microscopy experiments and analysed the TEM data with D.A and C.R. J.N carried out the STEM simulations. Q.W, H.G and D.L carried out the numerical simulations. All authors contributed to the preparation of the paper. H.G and J.N supervised the project. 